\title{
Democratic transformation in Hungary 1990-1997 a cross examination
}

\author{
Roel Popping
}

Published online: 14 January 2012

(C) The Author(s) 2012. This article is published with open access at Springerlink.com

\begin{abstract}
This paper presents a cross examination of findings from a content analytic study into the ideological implications of the democratic transformation in Hungary during the first years after the transition. For example, based on rhetoric within a sample of Hungarian editorials the study provides evidence of a shift between 1990 and 1997 in depictions of political activities from ones of achievement to ones of necessity. Support for these and other findings is sought and found in International Social Survey Program data from 1990, 1996, and 2006.
\end{abstract}

Keywords Hungary $\cdot$ Democratization $\cdot$ Cross examination

A recently published study of post-1989 ideological developments in Hungary (Roberts et al. 2009) affords an alternative approach to investigating changes in citizens' sociopolitical orientations than those based on election and survey results. The study applies modality analysis (Roberts et al. 2010) to rhetoric found in a probability sample of newspaper editorials published during the seven years immediately following the country's first post-Soviet democratic election. This paper is a validation study in which findings from the 2009 paper are "cross-examined" in light of data from elections and surveys collected during the paper's study period.

\section{Post-1989 East-Central Europe}

The previous century has witnessed the development of three general sociopolitical forms in Europe. Two have failed, namely the fascist and the communist models. The one surviving form is that of the liberal democratic state (Crook et al. 1992). Although other systems have developed in some Third World countries, it is toward liberal democracies that post-1989 East-Central Europe has evolved.

R. Popping ( $\varangle)$

Department of Sociology, University of Groningen, Groningen, The Netherlands

e-mail: r.popping@rug.nl 
Yet liberal democracies themselves are usually differentiated in accordance with three sociopolitical orientations, namely neo-liberal, a social-democratic, and populist. Following (Ost 1993, p. 475), a bourgeois-liberal (or neo-liberal) orientation stipulates that the "socialist economy must be transformed as quickly as possible into a capitalist market economy, with private property and free movement of capital." The populist orientation emphasizes both existing interests such as those of small-scale business and peasant entrepreneurship, as well as protectionism against foreign influence. The social-democratic orientation envisions society as a "corporation" in which people value workers' participation as well as "strong social welfare provisions on economic as well as on moral grounds" (Ost 1993, p. 477). (See Comisso 1997 for a similar depiction of these three sociopolitical orientations, albeit less based on economic interests than on cultural-ideological factors.)

Ost argues that East-Central European public policies are justified in terms of all three of these orientations. Yet there may be a developmental sequence among them. At the outset most East-Central European peoples desire neo-liberalism, and the riches they associate with it - a position consistent with early studies by Adam et al. (2008); Bigler (1991); Bluhm (2010); Ciobanu (2010); Kovács and Maggard (1993); Michta (1994); Szelényi et al. (1996); Tomka (2006); Waller (1994b), among others. Next, privatization and other neo-liberal reforms inevitably produce inflation and unemployment (Ringen and Wallace, 1994; Stark 1994), leading to populist resistance (Marks 2006; Sik 1994). Then as longstanding governments gain an air of permanence, state-sector workers will likely demand corporatism as a means of securing their interests in contrast to the competing interests of the bourgeois neo-liberals and the populists

According to Ost these orientations are not equally strong in all countries. The orientation most widely adopted by a liberal democratic state's citizens determines the policies pursued by the politicians in their country.

Citizens with a neo-liberal viewpoint will likely wish the transformations (especially capitalist reforms) implemented much faster than may be realistic. On the other hand, citizens, for whom changes are occurring too fast, may react by advocating an expedient exchange of democracy for a strong centralized government that will lessen the speed and thus the pain of reform. Such populist reactions are often embedded in appeals to national pride, to ethnic rights, to xenophobic concerns, etc. (Calhoun 2007; Lazda 2009; Schöpflin 1991; SurzhkoHarned 2010, Wal Waller 1994a; but also see Dobson and Dobson and Grant (1992) and Sztompka (1996) on political apathy and distrust). As is clear from the social movement literature, widespread expressions of this sort are likely to foreshadow the emergence of antidemocratic movements, and the possible demise of a democracy.

Part of the data used for this study (see later) has also been used by Lipsmeyer and Lipsmeyer and Nordstrom (2003). They concluded based on data from 1996 that opinions with respect to the government's responsibilities are comparable for respondents from Eastern and Western Europe. But with respect to government's spending in the fields of health care, pensioning, education and unemployment respondents in Eastern Europe preferred higher expenditures than respondents in the West. The authors did not investigate developments over time.

\section{Votes and voting intentions}

Most empirical work on changes of sociopolitical orientation in East-Central Europe has been based on inferences drawn from election and polling results. For example, Körösényi et al. (2009), p. 224 report an increase of over $17 \%$ in votes for socialist parties and a decrease of 


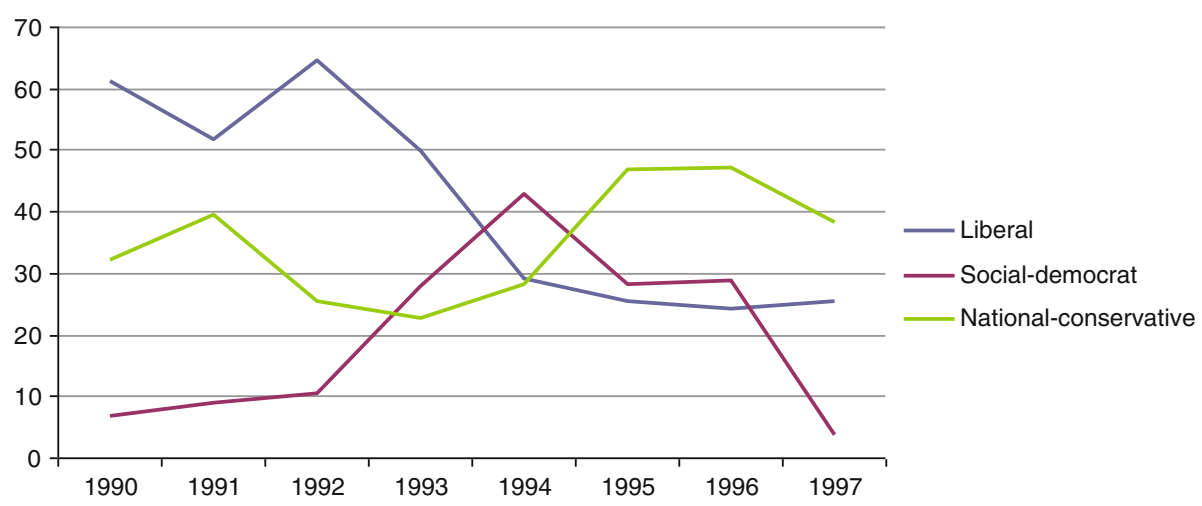

Fig. 1 Percentage of votes for liberals, social-democrats and national-conservatives in the CEEB-data

almost $13 \%$ for national conservative parties between Hungary's 1990 and 1994 elections. $^{1}$ A more detailed examination of the same trend is evident in annual Central and Eastern Euro-Barometer (CEEB) surveys between 1990 and 1997, where respondents were asked which party they were willing to vote for "if elections were held today." Figure 1 shows the socialist vs. liberal odds of Hungarians' willingness to have increased over this period-a trend, incidentally, that extends well beyond our study period as socialists maintained their parliamentary presence until a resurgence of support for conservative parties in the 2010 election.

Yet these voting-related measures are rather coarse indicators of shifts in sociopolitical orientation. For example, the switch in 2010 from socialist to conservative leadership in the Hungarian parliament may be evidence more of a turn to populism than of one to neo-liberalism (Palonen 2009). A more fine-grained approach to analyzing popular perspectives may be, as Roberts et al. (2010) suggest, to consider them as manifest in rhetorical arguments that people accept as reasonable bases for debating national issues.

\section{The study to be cross-examined}

According to Roberts et al. (2009), the rhetoric of social-democracy-a modality of necessity-is one of inevitabilities that are responsibly met for welfare-related reasons, whereas that of neo-liberalism — a modality of achievement-is one of possibilities that are opportunistically pursued for economic reasons.

Given that within a modality of necessity modal statements tend to convey a collaborator's requirements, rationales for these requirements will likely reference responsibilities unmet by the collaborator. In contrast, given that within a modality of achievement modal statements tend to convey an agent's possibility of success, rationales for such success will likely reference promising opportunities available to the agent (p. 508).

1 Both here and in Figure 1, socialist parties are Hungarian Socialist Party (MSzP), Hungarian Workers party (MSzMP) and (in 1990) Patriotic Election Coalition. The national conservatives are Hungarian Democratic Forum (MDF), Party of the Republic (KP), Smallholders Party (KGP), Christian Democratic Party (KDNP) and Hungarian Justice and Life Party (MIEP). The (neo) liberal parties are the left-liberal Federation of Free Democrats (SzDSz), and the right-liberal Federation of Young Democrats-Hungarian Civic Party (FIDESz), Liberal Citizens Alliance-Entrepeneurs Party (LPSz-P) and the Agrarian Federation (ASz). 
In their subsequent modality analysis of editorials within the Hungarian newspaper, Népszabadság (People's Freedom), these authors were able to demonstrate that during the years 1990-1997 the modality of Hungary's political discourse transformed from one of achievement (based on market justice among competitors) to one of necessity (based on social justice for the masses). In contrast, Hungarian editorialists' economic rhetoric was characterized by a drop in references to austerity (i.e., economic necessities) at the time of the 1994 election, but by increased references to possibilities when economic rationales were given in editorialists' modal arguments. However, since there was an overall decline in their use of economic rationales during the study period, there was a net decline in the editorialists' references to economic opportunities between 1990 and 1997. In brief, as late as 1997 their analysis provides evidence consistent with Ost's (1993) hypotheses that in East-Central European national discourse (here, as reflected in Hungary's largest domestic newspaper) a social-democratic orientation (political necessity) strengthened while populist (political possibility) and neo-liberal (economic possibility) ones weakened.

Validation of Roberts et al. (2009) thus requires evidence from an alternative source that is consistent with the following three hypotheses:

H1: There was an increase between 1990 and 1997 in Hungarians' public support for political reasons for necessary (presumably, socially responsible) activities.

H2: There was a decrease between 1990 and 1997 in Hungarians' public support for political reasons for possible (presumably, populist) activities.

H3: There was an increase between 1990 and 1997 in Hungarians' public support for economic reasons for possible (presumably, intervention by the administration) activities.

A fourth hypothesis should deal with the economic reasons for inevitable (decrease until 1995 and from then on increase), but no data variables are available in ISSP — see later- to test this.

\section{Data}

This article tests the robustness of Roberts et al. (2009) findings by comparing them to parallel results from other sources. The voting and CEEB data mentioned above are only a crude first step in this direction, given the consistency in the article's findings with the Hungarian electorate's shift in preferences to socialist from more conservative political parties during the period in question. We now turn to data from the International Social Survey Program's (ISSP) 1990, 1996, and (for comparison purposes) 2006 surveys - the only currently available data on Hungarians' attitudes toward their government at the requisite times.

In our quest for appropriate validation data (both in Hungary and internationally), we searched among archived data sets for repeatedly used items that might conceivably measure sociopolitical orientation relevant to political or economic rationales for possible or inevitable actions. ISSP surveys are the product of ongoing cross-national collaboration for the production of data on topics important for social science research. Our use is of ISSP data that include probability samples of 809 adult Hungarian citizens in 1990, of 1,149 in 1996 and of 772 in 2006. In all three surveys identical batteries of questions were asked about the role of the government in both political and economic domains. The questions that have been asked fit very well in the theory on welfare capitalism as was developed by Esping-Andersen (1990). This makes the range is more restricted than in the text analysis study.

This subsection describes three scales that we developed to test each of the three abovementioned hypotheses. In developing each scale, respondents' answers to a battery of items 
were dichotomized and Mokken's one-dimensional cumulative scaling model Mokken (1971); Van Schuur (2003) was fit to the answers, yielding scales that we could then evaluate in terms of their homogeneity, an indication for the degree in which all constituent variables approximate a hierarchical scale, and reliability, the degree to which the variables approximate an internally consistent scale. These evaluations were then performed for the total sample (across years) and for the samples in each year. Respondents who failed to answer one or more items in a battery were eliminated from the sample. This resulted in a loss of $168(17.2 \%)$ cases in $1990,351(23.4 \%)$ cases in 1996, and $238(23.6 \%)$ cases in 2006. An item was only included in a scale if its coefficient, Loevinger's H, reached .30 and its reliability (rho) was over .50. See the appendix for more detail on our construction of these Mokken scales.

\subsection{Political inevitability}

In the ISSP survey respondents were asked, "On the whole do you think it should or should not be the government's responsibility to..." perform each of nine activities on a 4-point scale from "definitely should not be" to "definitely should be." After collapsing these items into dummy variables (with $1=$ "should" and $0=$ "should not") for Mokken scaling, only three of the nine activities were suitable for scaling: "provide living standard for unemployed," "provide decent housing," and "provide health care for sick." (See Table 2 in the appendix for more detail.) Since these three activities are welfare-related and since they are ones respondents indicated as ones the government should, inevitably, do, we shall use this scale as the measure of "public support for political reasons for necessary, socially responsible activities" called for in a test of our first hypothesis (H1).

\subsection{Political possibility}

ISSP respondents were also asked, "Listed below are various areas of government spending. Please show whether you would like to see more of less government spending in each area", followed by a list of 8 potential spending areas. Possible responses were on a 5-point scale from "much less" to "much more" with a mid-point of "spend the same as now." Responses were collapsed into values of $1=$ " "more" or "much more", and $0=$ "same or less." In order of decreasing popularity, the six spending areas that met our scaling criteria are as follows: "health," "education," "environment," "law enforcement," "culture and arts," and "defense." (See Table 3 in the appendix for more detail.) Our thinking is that the "whether you would like to see" wording used in this set of items suggests more of a reference to "possible" than to "inevitable" political activity. Thus (admittedly, at a bit of a stretch) we suggest that this scale might be used as the measure of "public support for political reasons for possible (presumably, populist) activities" called for in a test of $\mathrm{H} 2$.

\subsection{Economic possibility}

Finally, there is the battery of ISSP items asking, "Here are some things the government might do for the economy. Please show which actions you are in favor and which you are against", followed by a list of six possible economic policies. Of these six, our scale includes data on the following four policies: "reduce working week for more jobs," "support declining industries to protect jobs," "support industry to develop new products," and "financing projects for new jobs." As with the other scales, original responses (one a 5-point scale from "strongly in favor of" to "strongly against") were dichotomized into $1=$ "(strongly) in favor 
Table 1 Mean differences on three Mokken scales between pairs of years

\begin{tabular}{|c|c|c|c|c|c|c|c|c|c|c|}
\hline \multirow[t]{2}{*}{ Scale } & \multicolumn{3}{|c|}{ Means } & \multicolumn{2}{|c|}{ 1990-1996 } & \multicolumn{2}{|c|}{ 1990-2006 } & \multicolumn{2}{|c|}{ 1996-2006 } & Overall \\
\hline & $\bar{X}_{90}$ & $\bar{X}_{96}$ & $\bar{X}_{06}$ & $\Delta_{1}$ & $p_{1}$ & $\Delta_{2}$ & $p_{2}$ & $\Delta_{3}$ & $p_{3}$ & $F_{2727}^{2}$ \\
\hline Political inevitability & 2.56 & 2.39 & 2.45 & -.17 & $<.01$ & \multicolumn{2}{|c|}{$-.10<.01$} & .07 & .02 & $13.21<.01$ \\
\hline Political possibility & 4.03 & 3.89 & 3.49 & -.14 & .02 & \multicolumn{2}{|c|}{$-.54<.01$} & -.40 & $<.01$ & $28.26<.01$ \\
\hline Economic possibility & 2.57 & 2.81 & 2.92 & .24 & $<.01$ & \multicolumn{2}{|c|}{$.35<.01$} & .10 & .02 & $24.03<.01$ \\
\hline
\end{tabular}

Note $P$-values for mean differences are one-tailed

of" and $0=$ " "neither in favor of nor against' or "(strongly) against"” prior to scaling. Given that the scale refers to possible economic policies, we shall be using it as our measure of "public support for economic reasons for possible (presumably, government intervention) activities" in testing $\mathrm{H} 3$.

The score on each scale consists of the contributing number of items that is supported. Given these three scales, we can now proceed to a cross examination, or validation, of the findings in Roberts et al. (2009). The following section takes up this task.

\section{Cross examination}

The validation performed here is intended to evaluate the robustness of a new content analysis technique for measuring changes in citizens' sociopolitical orientation over time. Our cross examination investigates whether results using the technique (namely those in Roberts (2008)) can be supported using alternative measures from another dataset. In qualitative research such cross examination is referred to as "triangulation." More specifically, it refers to the application and combination of research methodologies in the study of the same phenomenon.

Overall F-texts in the right-most columns of Table 1 show that there are significant differences in scale scores among the 3 years. Most important for our purposes are the mean differences between 1990 and 1996 scores on each scale. Confirmation consistent with hypotheses 2 and 3 is found in a significant decrease in support for more government spending in Hungary and increase in support for possible economic policies. The expected increase in Hungarians' indications that three social welfare policies should be their government's responsibility is not supported.

The text analysis study did show a decrease in attention for the politics rhetoric that is possible. The second scale shows that between 1990 and 1996 a comparable result is found. The number of activities possible to the administration is decreasing. This decreasing tendency is continued in the next years to come, 1996-2006. The economics rhetoric that is possible increased over time in the text analysis study. This is also found in our third scale. We also see that the increase continues in the later years. The politics rhetoric that is inevitable increased between 1990 and 1997 in the text analysis study. In the present study there is a decrease between 1990 and 1996, but between 1996 and 2006 there is an increase.

The first two results mentioned here are similar to the ones in the text analysis study. The last result is slightly different. The general tendency is the same, but there is as it were some delay. In part this might be due to the moment at which the data had been collected. It might also be due to the fact that actually here a characteristic is measured that has some overlap with the characteristic measured in the text analysis study, but there is not that much overlap. For the other characteristics that are measured, the overlap is greater. 


\section{Conclusion}

From the cross-examination two conclusions might be drawn. The first conclusion is that the results from the text analysis study are confirmed in the present study. It must be noted however that the range of the scales found in the ISSP study is far more limited than the range of the data from the text analysis study and that in the survey data there seems to be a delay with regard to public support for political reasons for necessary, socially responsible activities. Nevertheless, these results cause that even more confidence in the original findings is permitted. In Hungary's political discourse attention for the possible has decreased between 1990 and 1997. The attention here for the inevitable first decreased, but later on it increased again. Hungary's economic discourse on the possible transformed in the expected direction during this time. An examination for the economic discourse on the inevitable can not be performed as no survey data are found for a comparison.

A second conclusion is that it is hard to find good data for a cross examination. In part this is because the research questions are different. The questions posed in a text analysis study are slightly different from the ones asked in a survey. But apart of that there are not that much data sets containing scores on comparable very specific questions measured for the same period and the same place.

Anyway however, at face value comparative developments are expected. If not there would have been a problem. Now we know that in a broad sense the findings from the survey support the text analysis findings.

The items in the survey actually express only part of what is covered in the text analysis study. Although we realize this is not that much, we also know it is based on the only comparison we could make. The survey data also indicate a change between 1996 and 2006. If a follow up of the text analysis study would be performed, this suggestion might be used as one underpinning, to be extended with others, for the formulation of hypotheses for that study.

\section{Appendix—details on the Mokken scale analyses}

Scales used for cross examination (calculated based on "all" 2730 cases) each have H(i)-values greater than .30 on each item. In addition, both overall and for at least 2 of the 3 years the scales have values of Loevinger's $H$ of at least .30 and of rho greater than .50 . In this appendix's three tables, $\mathrm{p}$ (i) scores refer to the probability of a positive answer to the item and $\mathrm{H}(\mathrm{i})$-scores refer to the homogeneity, the indication for the degree in which all constituent variables approximate a hierarchical scale (See Table 2).

Although 9 items were mentioned on the ISSP surveys that might contribute to the measurement of public support for political reasons for necessary, socially responsible activities, $\mathrm{H}(\mathrm{i})$-scores on only 5 of them formed a scale (i.e., H(i)-scores on the other 4 items were below .30-the minimal acceptable value according to Mokken (1971)). This 5-item scale $(\mathrm{H}=.40)$ consisted of the first three items listed above plus "provide living standard for the old" and "financial help to students." In 1996 and 2006 respectfully 7 and 6 items form a scale. Yet for 1990 only two of the 9 items form a scale, namely the ones listed above with $\mathrm{H}(\mathrm{i})$-scores greater than .30 for that year. For our purposes we shall use the scale consisting of 3 items that fit in all of the separate years, plus the one item that fits overall and in 1996 and 2006, plus "almost fits" in 1990 (namely, "provide health care for sick," with H(i) = .29) (See Table 3). 
Table 2 Political inevitability, as measured by responses to, "On the whole do you think it should or should not be the government's responsibility to..." $(0=$ no, $1=$ yes $)$

\begin{tabular}{|c|c|c|c|c|c|c|c|c|}
\hline \multirow[t]{2}{*}{ Item } & \multicolumn{2}{|l|}{ All } & \multicolumn{2}{|c|}{1990} & \multicolumn{2}{|c|}{1996} & \multicolumn{2}{|l|}{2006} \\
\hline & $\mathrm{p}(\mathrm{i})$ & $\mathrm{H}(\mathrm{i})$ & $\mathrm{p}(\mathrm{i})$ & $\mathrm{H}(\mathrm{i})$ & $\mathrm{p}(\mathrm{i})$ & $\mathrm{H}(\mathrm{i})$ & p(i) & $\mathrm{H}(\mathrm{i})$ \\
\hline Provide living standard for unemployed & .68 & .40 & .73 & .32 & .64 & .44 & .70 & .40 \\
\hline Provide decent housing & .78 & .39 & .84 & .31 & .75 & .42 & .76 & .41 \\
\hline Provide health care for sick & .99 & .46 & .99 & .29 & .99 & .71 & .99 & .32 \\
\hline Reduce income differences & .80 & & .81 & & .78 & & .84 & \\
\hline Control prices & .87 & & .90 & & .87 & & .85 & \\
\hline Provide job for everyone & .88 & & .89 & & .86 & & .90 & \\
\hline Help industry grow & .89 & & .89 & & .89 & & .89 & \\
\hline Financial help to students & .91 & & .91 & & .90 & & .92 & \\
\hline Provide living standard for the old & .99 & & .99 & & .98 & & .99 & \\
\hline $\mathrm{H}$ & & .40 & & .31 & & .44 & & .40 \\
\hline Rho & & .55 & & .36 & & .49 & & .50 \\
\hline
\end{tabular}

Table 3 Political possibility, as measured by responses to, "Listed below are various areas of government spending. Please show whether you would like to see more of less government spending in each area?" $(0=$ less, $1=$ more)

\begin{tabular}{|c|c|c|c|c|c|c|c|c|}
\hline \multirow[t]{2}{*}{ Item } & \multicolumn{2}{|l|}{ All } & \multicolumn{2}{|l|}{1990} & \multicolumn{2}{|l|}{1996} & \multicolumn{2}{|l|}{2006} \\
\hline & $\mathrm{p}(\mathrm{i})$ & $\mathrm{H}(\mathrm{i})$ & $\mathrm{P}(\mathrm{i})$ & $\mathrm{H}(\mathrm{i})$ & $\mathrm{p}(\mathrm{i})$ & $\mathrm{H}(\mathrm{i})$ & p(i) & $\mathrm{H}(\mathrm{i})$ \\
\hline Defense & .24 & .45 & .14 & .38 & .32 & .48 & .24 & .48 \\
\hline Culture and arts & .54 & .38 & .65 & .25 & .49 & .42 & .48 & .42 \\
\hline Law enforcement & .57 & .36 & .54 & .24 & .65 & .37 & .47 & .42 \\
\hline Environment & .72 & .39 & .87 & .37 & .67 & .34 & .64 & .45 \\
\hline Education & .82 & .47 & .88 & .35 & .83 & .45 & .74 & .54 \\
\hline Health & .94 & .49 & .95 & .33 & .93 & .47 & .92 & .64 \\
\hline Unemployment benefits & .40 & & .48 & & .34 & & .41 & \\
\hline Retirement & .82 & & .87 & & .84 & & .74 & \\
\hline $\mathrm{H}$ & & .41 & & .30 & & .41 & & .47 \\
\hline Rho & & .63 & & .55 & & .65 & & .71 \\
\hline $\mathrm{N}$ & & 2730 & & 809 & & 1149 & & 772 \\
\hline
\end{tabular}

Among the 8 items mentioned on the ISSP surveys hopefully contributing to public support for political reasons for possible activities, H(i)-scores on two of them (regarding government spending on "retirement" and "unemployment benefits") were below .30 in all nalyses. Accordingly, the scale used in our cross examination excludes these two items. Although the left out items themselves form a separate scale $(\mathrm{H}=.57$, rho $=.45)$, we do not make use of this two-item scale in the cross examination. Looking at the separate years, the scale consisting of the six remaining items is also found in 1996 and 2006. The items "culture and art" and "law enforcement" have small H(i)-values in 1990. But since the scale fits for the 
Table 4 Economic possibility, as measured by responses to, "Here are some things the government might do for the economy. Please show which actions you are in favor and which you are against." $(0=$ not do, $1=$ do $)$

\begin{tabular}{|c|c|c|c|c|c|c|c|c|}
\hline \multirow[t]{2}{*}{ Item } & \multicolumn{2}{|l|}{ All } & \multicolumn{2}{|l|}{1990} & \multicolumn{2}{|l|}{1996} & \multicolumn{2}{|l|}{2006} \\
\hline & $\mathrm{p}(\mathrm{i})$ & $\mathrm{H}(\mathrm{i})$ & $\mathrm{p}(\mathrm{i})$ & $\mathrm{H}(\mathrm{i})$ & $\mathrm{p}(\mathrm{i})$ & $\mathrm{H}(\mathrm{i})$ & $\mathrm{p}(\mathrm{i})$ & $\mathrm{H}(\mathrm{i})$ \\
\hline Reduce working week for more jobs & .40 & .40 & .44 & .32 & .38 & .41 & .40 & .60 \\
\hline Support declining industries to protect jobs & .61 & 43 & .48 & .35 & .63 & .41 & .72 & .54 \\
\hline Support industry to develop new products & .87 & .37 & .88 & .24 & .88 & .42 & .85 & .51 \\
\hline Financing projects for new jobs & .89 & .30 & .77 & .20 & .93 & .44 & .95 & .37 \\
\hline Less government regulations of business & .59 & & .74 & & .53 & & .52 & \\
\hline Cut government spending & .87 & & .81 & & .91 & & .87 & \\
\hline $\mathrm{H}$ & & .38 & & .28 & & .42 & & .52 \\
\hline Rho & & .54 & & .51 & & .52 & & .62 \\
\hline $\mathrm{N}$ & & 2730 & & 809 & & 1149 & & 772 \\
\hline
\end{tabular}

complete sample and for the other two years and since the $\mathrm{H}=-$ value for the total scale still just fits, we continue with this scale (See Table 4).

After starting with six items for public support for economic reasons for possible activities, two (namely, "less government regulations of business" and "cut government spending") were excluded because their H(i)-values were smaller than the criterion of .30. After dropping these two items the above scale is found. In the separate years the scale consisting of 4 items is also found, with the exception that in 1990 the H(i)-values for "financing projects for new jobs" and "support industry to develop new products" are below the criterion. This is not surprising, given the lack of government resources at the time relative to later years. But since the scale fits for the complete sample and the other two years, we continue with this scale, just as we did with the previous scale.

Open Access This article is distributed under the terms of the Creative Commons Attribution Noncommercial License which permits any noncommercial use, distribution, and reproduction in any medium, provided the original author(s) and source are credited.

\section{References}

Adam, F., Tomsic, M., Kristan, P.: Political elite, civil society, and type of capitalism: Estonia and Slovenia. East Eur. Q. 42(1), 43-64 (2008)

Bigler, R.M.: From communism to democracy: Hungary's transition thirty-five years after the revolution. East Eur. Q. 25(4), 437-461 (1991)

Bluhm, K.: Theories of capitalism put to the test: introduction to a debate on central and eastern Europe. Hist. Soc. Res. 35(2), 197-217 (2010)

Calhoun, C.: Nationalism and cultures of democracy. Public Cult. 19(1), 151-173 (2007)

Ciobanu, M.: Communist regimes, legitimacy and the transition to democracy in eastern Europe. National. Papers 38(1), 3-21 (2010)

Comisso, E.: Is the glass half full or half empty? reflections on five years of competitive politics in eastern Europe. Communist Post-Communist Stud. 30(1), 1-21 (1997)

Crook, S., Pakulski, J., Waters, M.: Postmodernism. Change in advanced society. Sage, London (1992)

Dobson, R.B., Grant, S.A.: Public opinion and the transformation of the Soviet Union. Int. J. Public Opin. Res. 4(4), 302-320 (1992)

Esping-Andersen, G.: The three worlds of welfare capitalism. Polity Press, Cambridge (1990) 
Körösényi, A., Toth, Cs., Török, G.: The Hungarian political system. Hungarian Center for Democracy Studies Foundation, Budapest (2009)

Kovács, D., Maggard, S.W.: The human face of political, economic, and social change in eastern-Europe. East Eur. Q. 27(3), 317-349 (1993)

Lazda, M.: Reconsidering nationalism: the Baltic case of Latvia in 1989. Int. J. Politics Cult. Soc. 22(4), 517-536 (2009)

Lipsmeyer, C.S., Nordstrom, T.: East versus West: comparing political attitudes and welfare preferences across European societies. J. Eur. Public Policy 10(3), 339-364 (2003)

Marks, B.: Radicals in central Europe: real danger or a passing fad. Pol. Sociol. Rev. 154, 209-230 (2006)

Michta, A.A.: The government and politics of postcommunist Europe. Praeger, Westport (1994)

Mokken, R.J.: A theory and procedure of scale analysis. Mouton, The Hague (1971)

Ost, D.: The politics of interest in post-communist east Europe. Theory Soc. 22(4), 453-486 (1993)

Palonen, E.: Political polarisation and populism in contemporary Hungary. Parliam. Aff. 62(2), 318-334 (2009)

Roberts, C.W.: The fifth modality: on languages that shape our motivations and cultures. Brill, Leiden (2008)

Roberts, C.W., Popping, R., Pan, Y.: Modalities of democratic transformation: forms of public discourse within Hungary's largest newspaper, 1990-1997. Int. Soc. 24(4), 498-525 (2009)

Schöpflin, G.: National identity in the Soviet Union and east central Europe. Ethn. Racial Stud. 14(1), 3-14 (1991)

Sik, E.: The vulture and the calamity (or, why were Hungarian taxi drivers able to rebel?). In: Kováks, J.M. (ed.) Transition to capitalism? the communist legacy in eastern Europe., pp. 275-289. Transaction, New Brunswick (1994)

Stark, D: Path dependence and privatization strategies in east central Europe. In: Kováks, J.M. (ed.) Transition to capitalism? the communist legacy in eastern Europe, pp. 63-100. Transaction, New Brunswick (1994)

Surzhko-Harned, L.: Liberal nationalism, nationalist liberalization, and democracy: the cases of post-Soviet Estonia and Ukraine. National. Papers 38(5), 623-646 (2010)

Szelényi, Sz., Szelényi, I., Poster, W.: Interests and symbols in post-communist political culture: the case of Hungary. Am. Sociol. Rev. 61(3), 466-477 (1996)

Sztompka, P.: Trust and emerging democracy. Int. Sociol. 11(1), 37-62 (1996)

Tomka, B.: East central Europe and the European social policy model: long-term view. East Eur. Q. 40(2), 135-159 (2006)

Van Schuur, W.H.: Mokken scale analysis: between the Guttman scale and parametric item response theory. Political Anal. 11(2), 139-163 (2003)

Waller, M: Voice, choice and loyalty: democratization in eastern Europe. In: Parry, G., Moran, M. (eds.) Democracy and democratization, pp. 129-151. Routledge, New York (1994)

Waller, M: Winners and losers in the early post-communist elections in east-central Europe. In: Waller, M., Coppieters, B., Deschouwer, K. (eds.) Social democracy in a post-communist Europe, pp. 84-102. Frank Cass, Portland (1994)

Weiner, R.: Change in eastern Europe. Praeger, Westport (1994) 